\title{
Guest editors' introduction to feature section: bariatric surgery
}

\author{
Stephen W. Trenkner, ${ }^{1}$ Alexander R. Margulis, ${ }^{2}$ Alfons Pomp ${ }^{3}$ \\ ${ }^{1}$ Department of Radiology, Mayo Clinic, 200 First Street SW, Rochester, MN 55905, USA \\ ${ }^{2}$ Weill Cornell Medical College, 525 East 68th Street, F-053, New York, NY 10065, USA \\ ${ }^{3}$ Section of Laparoscopic and Bariatric Surgery, Department of Surgery, Weill Medical College of Cornell University, New York \\ Presbyterian Hospital, 525 East 68th Street, New York, NY 190065, USA
}

Why devote a feature section of abdominal imaging to bariatric surgery?

The prevalence of obesity in the United States continues to be high, now surpassing $30 \%$ in most age and sex groups after striking increases in the 1980s and 1990s [1]. Obesity is a risk factor for a variety of chronic health conditions from heart disease to cancer, but most importantly diabetes. The prevention and treatment of obesity, especially morbid obesity (BMI $>40$ ), is difficult and programs involving healthful eating and regular physical activity have limited results at best [2]. Surgery continues to be the only effective weight loss option for the morbidly obese. During the past decade, the safety of bariatric surgery has improved dramatically, the laparoscopic approach for gastric bypass has become mainstream and the laparoscopic adjustable gastric band was introduced. Since the beginning of the millennium, the number of in-patient bariatric surgery discharges has increased to about 125,000 per annum with an $80 \%$ decrease in mortality (from $0.8 \%$ in 1998 to $0.1 \%$ in 2008) [3]. Weight loss surgery cases require expert radiologic imaging to evaluate the anatomy and assess complications. While initially, fluoroscopic contrast studies were more common, many of the anatomic alterations secondary to the surgery require computed tomography for appropriate diagnosis.

The history of bariatric surgery begins with the jejunoileal bypass first performed in the 1950s at the University of Minnesota. When the unacceptably high rate of complications of these operations became more obvious, the gastric bypass, initially championed by Edward Mason, appeared on the surgical horizon in the 1960s. Seeking to decrease the metabolic side effects of

Correspondence to: Stephen W. Trenkner; email: trenkner.stephen@, mayo.edu the operation, the vertical banded gastroplasty (VBG) was introduced, in the 1980s [4]. Unfortunately, the VBG often required surgical revision and was even more frequently associated with inadequate weight loss and this procedure has also fallen out of favor [5]. There are, however, still many patients who have a VBG that require high-quality imaging. The laparoscopic adjustable gastric band was approved by the FDA in 2001. It has become popular among patients for it is perceived lack of life-threatening complications and adjustability, but more recently the literature has been less enthusiastic about this operation [6]. Beitner and Kurian, as well as Keane et al., review this surgery and applicable imaging. Carrucci and Turner review gastric bypass imaging and also discuss the more recently introduced sleeve gastrectomy with or without biliopancreatic diversion and duodenal switch [7, 8]. Roohipour and Herron then do an excellent job of describing the complications of bypass and sleeve gastrectomy. The next articles discuss what is being done to prevent and treat obesity without surgery in children as well as articles on bariatric surgery in children. The Feature Section concludes with papers discussing the causes of obesity and the psychology of obesity.

We consider this subject so important that we are presenting more than just imaging. Morbid obesity and its treatment have touched all aspects of the medical community. Besides radiologists, we have included articles by surgeons, internists, psychiatrists, and epidemiologists, and it is our intent that this Feature Section be read in it is entirety. Having a more complete understanding of this discipline is important for all physicians. Not only is it helpful in discussions with our patients, but also with employees, family members and neighbors. There is no aspect of our profession as radiologists and surgeons about which we get more questions than bariatric surgery. We certainly hope that the obesity epidemic will be more successfully addressed by the 
appropriate public health policies in the future. Currently, the prevalence of obesity, and consequently, surgery for weight loss, is such an important topic that we felt it necessary to provide this insight about the whole problem.

Acknowledgment. The editors and authors would like to thank Rachel Paulson for her outstanding work in helping prepare this journal.

\section{References}

1. Flegal KM, Carroll MD, Ogden CL, Curtin LR (2010) Prevalence and trends in obesity among US adults, 1999-2008. JAMA 303(3):235-241

2. Christiansen T, Bruun JM, Madsen EL, Richelsen B (2007) Weight loss maintenance in severely obese adults after an intensive lifestyle intervention: 2- to 4-year follow-up. Obesity (Silver Spring) 15(2): 413-420

3. Nguyen NT, Masoomi H, Magno CP, et al. (2011) Trends in use of bariatric surgery, 2003-2008. J Am Coll Surg 213(2):261-266

4. Buchwald H, Rucker RD (1981) The history of metabolic surgery for morbid obesity and a commentary. World J Surg 5(6):781-787

5. Balsiger BM, Poggio JL, Mai J, Kelly KA, Sarr MG (2000) Ten and more years after vertical banded gastroplasty as primary operation for morbid obesity. J Gastrointest Surg 4(6):598-605

6. Himpens J, Dapri G, Cadière GB (2006) A prospective randomized study between laparoscopic gastric banding and laparoscopic isolated sleeve gastrectomy: results after 1 and 3 years. Obes Surg 16(11):1450-1456

7. Prachand VN, Ward M, Alverdy JC (2010) Duodenal switch provides superior resolution of metabolic comorbidities independent of weight loss in the super-obese (BMI $>$ or $=50 \mathrm{~kg} / \mathrm{m}^{2}$ ) compared with gastric bypass. J Gastrointest Surg 14(2):211-220

8. Regan JP, Inabnet WB, Gagner M, Pomp A (2003) Early experience with two-stage laparoscopic Roux-en-Y gastric bypass as an alternative in the super-super obese patient. Obes Surg 13(6):861-864 